\title{
A FOETAL GROWTH TRAJECTORY IN ANTENATAL PERIOD AND ITS RELATION WITH BIRTH WEIGHT- A RECORD BASED ANALYSIS FROM RURAL KOKAN OF WESTERN MAHARASHTRA
}

\author{
Suvarna N. Patil ${ }^{1}$, Maruti B. Desai², Netaji R. Patil ${ }^{3}$, Vasant Yeshwantrao Kawade 4 \\ ${ }_{1}^{1}$ Medical Director and Physician, Department of Medicine, BKL Walawalkar Rural Medical College, Kasarwadi, Maharashtra. \\ ${ }^{2}$ Statistician-Cum-Research Associate, Department of Preventive \& Social Medicine, BKL Walawalkar Rural Medical College, \\ Kasarwadi, Maharashtra. \\ ${ }^{3}$ Radiologist, Department of Radio-diagnosis, BKL Walawalkar Rural Medical College, Kasarwadi, Maharashtra. \\ ${ }^{4}$ Professor, Department of Obstetrics \& Gynaecology, BKL Walawalkar Rural Medical College, Kasarwadi, Maharashtra.
}

\section{ABSTRACT}

\section{BACKGROUND}

Objective of this study is to assess ultrasonic foetal growth patterns and its comparison with known standards in relation to normal \& low birth weight in all trimesters, and to classify newborns based on ultrasonographic gestational age.

\section{MATERIALS AND METHODS}

It is a hospital record based retrospective analysis carried out on data from January 2012 to December 2015 in rural western Maharashtra. 1597 women with singleton pregnancy who underwent USG-scans and delivered in the hospital with completeness of records constituted the study population. Foetal growth trajectories are compared with International standards.

\section{RESULTS}

First and second trimester biometry findings are analogous to western chart, but not agreeable in late $3^{\text {rd }}$ trimester.

\section{CONCLUSION}

Study concluded that lag of foetal growth beyond 32-33 weeks of gestation may be attributed to compromised nutritional status of the mother.

\section{KEYWORDS}

Estimated Foetal Weight (EFW), Gestational Age (GA), Preterm, Low Birth Weight (LBW), Appropriate Gestational Age (AGA).

HOW TO CITE THIS ARTICLE: Patil SN, Desai MB, Patil NR, et al. A foetal growth trajectory in antenatal period and its relation with birth weight- A record based analysis from rural Kokan of Western Maharashtra. J. Evolution Med. Dent. Sci. 2017;6(33): 2676-2679, DOI: $10.14260 /$ Jemds/2017/577

\section{BACKGROUND}

Ultrasound has proved to be a useful and accurate method for determining gestational age (GA) of the foetus. The accurate knowledge of GA is the key for successful antenatal care and planning of appropriate intervention. Approximately, $20 \%$ of Indian infants are born with LBW.(1) Birth weight of a newborn is a prospective as well as retrospective marker of growth \& development. Thus became the prospective predictor. Alternatively it reflects maternal malnutrition retrospectively.(2) Proper assessment of foetal wellbeing requires an accurate knowledge of the gestational age of the foetus. Foetal size is usually categorised on the basis of estimated foetal weight (EFW) being small $\left(<10^{\text {th }}\right.$ percentile, SGA), appropriate $\left(10-90^{\text {th }}\right.$ percentile, AGA), or large (> 90th percentile, LGA) for gestational age. Traditionally, standards for birth weights for gestation have been based on the average of the population. Queries have been raised

\section{Financial or Other, Competing Interest: None.}

Submission 04-03-2017, Peer Review 12-04-2017,

Acceptance 17-04-2017, Published 24-04-2017.

Corresponding Author:

Maruti B. Desai,

Statistician-Cum-Research Associate,

BKL Walawalkar Rural Medical College,

Kasarwadi, Sawarde, Taluka-Chiplun,

District-Ratnagiri, Maharashtra, India.

E-mail: mbdresearch7571@gmail.com

DOI: $10.14260 /$ jemds $/ 2017 / 577$

regarding the applicability of these standard curves to a racially mixed population due to ethnic variations. There might be a risk of over-diagnosing intrauterine growth retardation in the Indian population. This study evaluates the validity of the standard growth curves proposed for Western populations to an Indian population. ${ }^{(3)}$ This paper discusses growth trajectory of normal, LBW and premature foetus \& its relation to birth weight. It also discusses the challenges of labelling Indian newborn as IUGR or LBW when very less no. of Indian studies are available for comparison where an average Indian mother is short and thin and gives birth to light \& thin baby.(4)

\section{MATERIALS AND METHODS}

It is a retrospective observational study carried out from January 2012 to December 2015 in a rural B.K.L. Walawalkar Hospital, Ratnagiri, Maharashtra. Women with singleton pregnancy who underwent USG-scans \& delivered in the hospital constituted the study population. Early dating \& subsequent scans were performed to measure foetal growth parameters viz. BPD, HC, AC, FL \& EFW, etc. by standardised machine \& method using real time USG convex probe of 3.5 $\mathrm{MHz}$ frequency with single observer. In immediate postpartum period, neonatal birth weights were recorded with standardised infant digital weighing scale. In total 3219 records are available with hospital, among them 1597 records fulfilled inclusion criteria of the study. Record based analysis was done for the same with the help of appropriate statistical software. Graphical \& comparative plots were made to establish and compare growth trajectories with International standards. For further analysis, babies were 
divided into three groups according to their growth trajectory, birth weight and gestational age. Classification was done by gestational age and intrauterine growth. Being a record based analysis few limitations may occur.

\section{Inclusion Criteria}

A woman with singleton pregnancy who underwent ultrasonography scans \& delivered in the hospital.

\section{Exclusion criteria}

A woman with twin pregnancy, no ultrasounds done at hospital, not delivered in the hospital or incomplete records.

\section{RESULTS}

1. Out of 3219 records available with hospital, 1597 records fulfilled inclusion criteria.

\begin{tabular}{|c|c|c|}
\hline Observation & N & Percentage \\
\hline Total newborns & 1597 & - \\
\hline Preterm & 199 & 12.46 \\
\hline Full Term LBW $(<2.5 \mathrm{~kg})$ & 504 & 31.56 \\
\hline Full Term Normal $(\geq 2.5 \mathrm{~kg})$ & 894 & 55.98 \\
\hline \multicolumn{2}{|c|}{ Table 1. Baseline Profile of Respondents } \\
\hline
\end{tabular}

2. Among preterm respondents, $10^{\text {th }}$ percentile value of EFW in study population showed decline after 32 wks. of gestation $\& 50^{\text {th }}$ percentile showed decline after $33 \mathrm{wks}$. while $90^{\text {th }}$ percentile declined after 34 wks. of gestation compared to Hadlock percentiles.

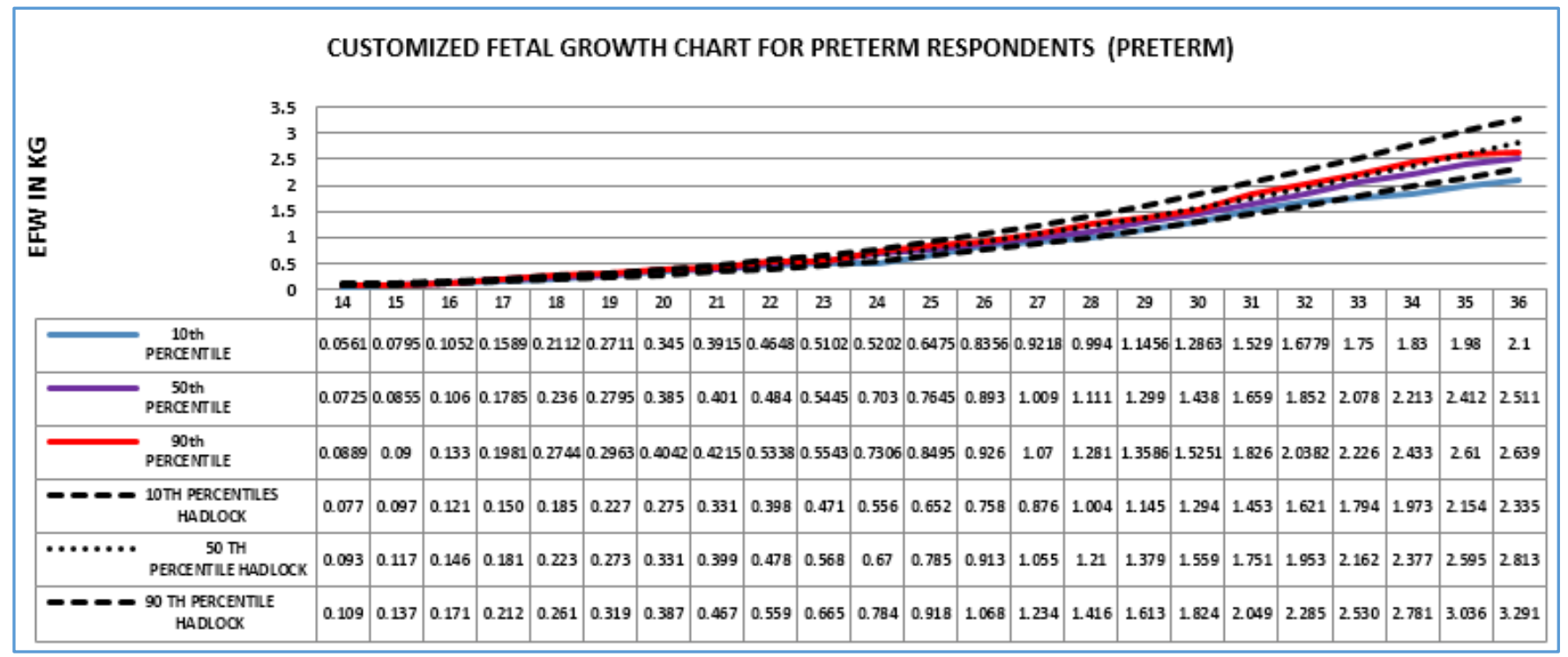

Table 2. Customised Foetal Growth Chart for Preterm Respondents (Preterm)

3. Amongst LBW fullterm respondents, $10^{\text {th }}$ percentile $\& 50^{\text {th }}$ percentile were slightly declined after 33 wks. \& $90^{\text {th }}$ percentile was slightly declined after 34 wks. of gestation compared to Hadlock percentiles. 


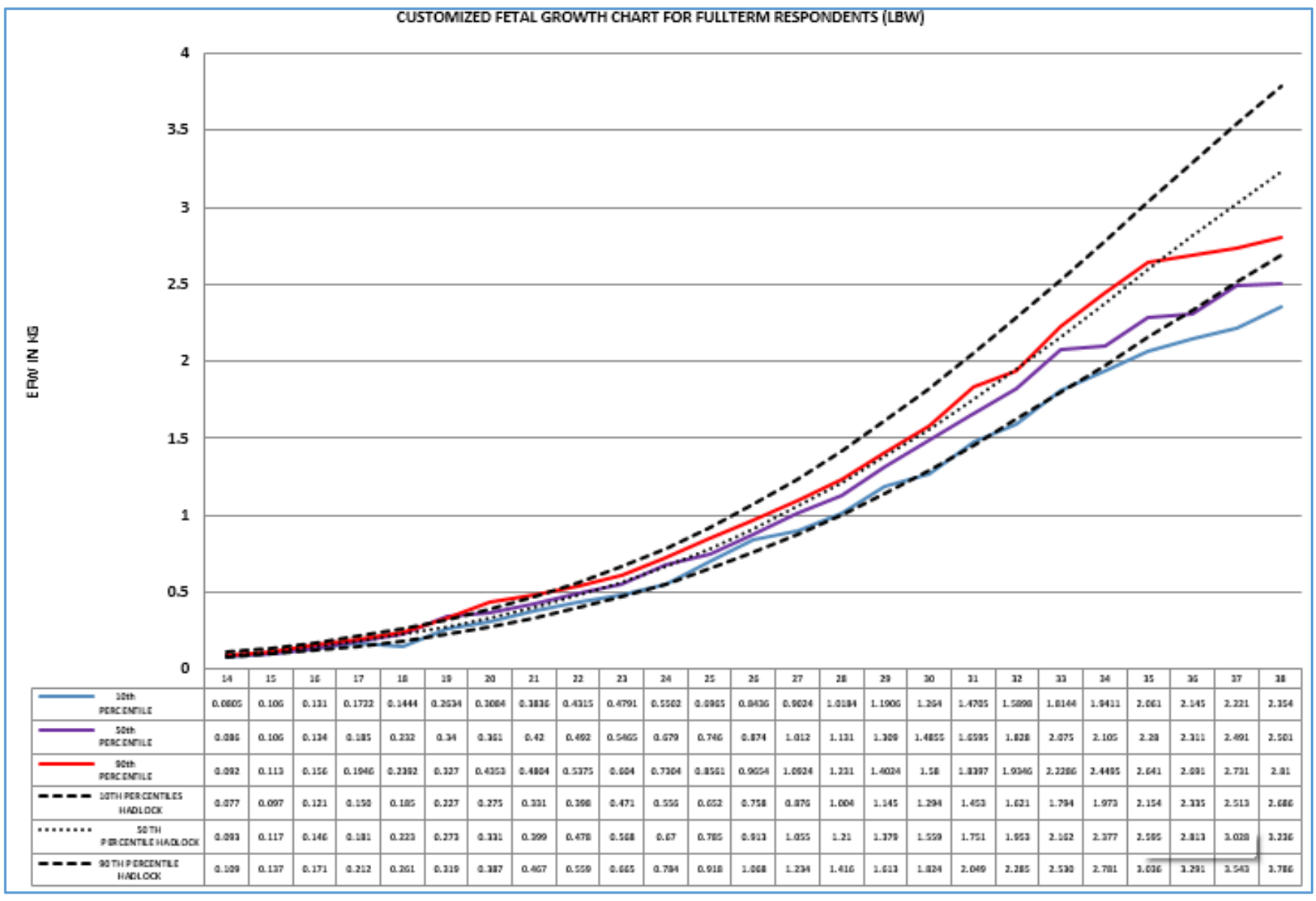

Table 3. Customised Foetal Growth Chart for Fullterm LBW Respondents

4. Among normal full-term respondents, $10^{\text {th }}, 50^{\text {th }} \& 90^{\text {th }}$ percentiles showed declining trends after $34,35 \& 36$ wks. of gestation respectively in comparison with Hadlock percentiles.

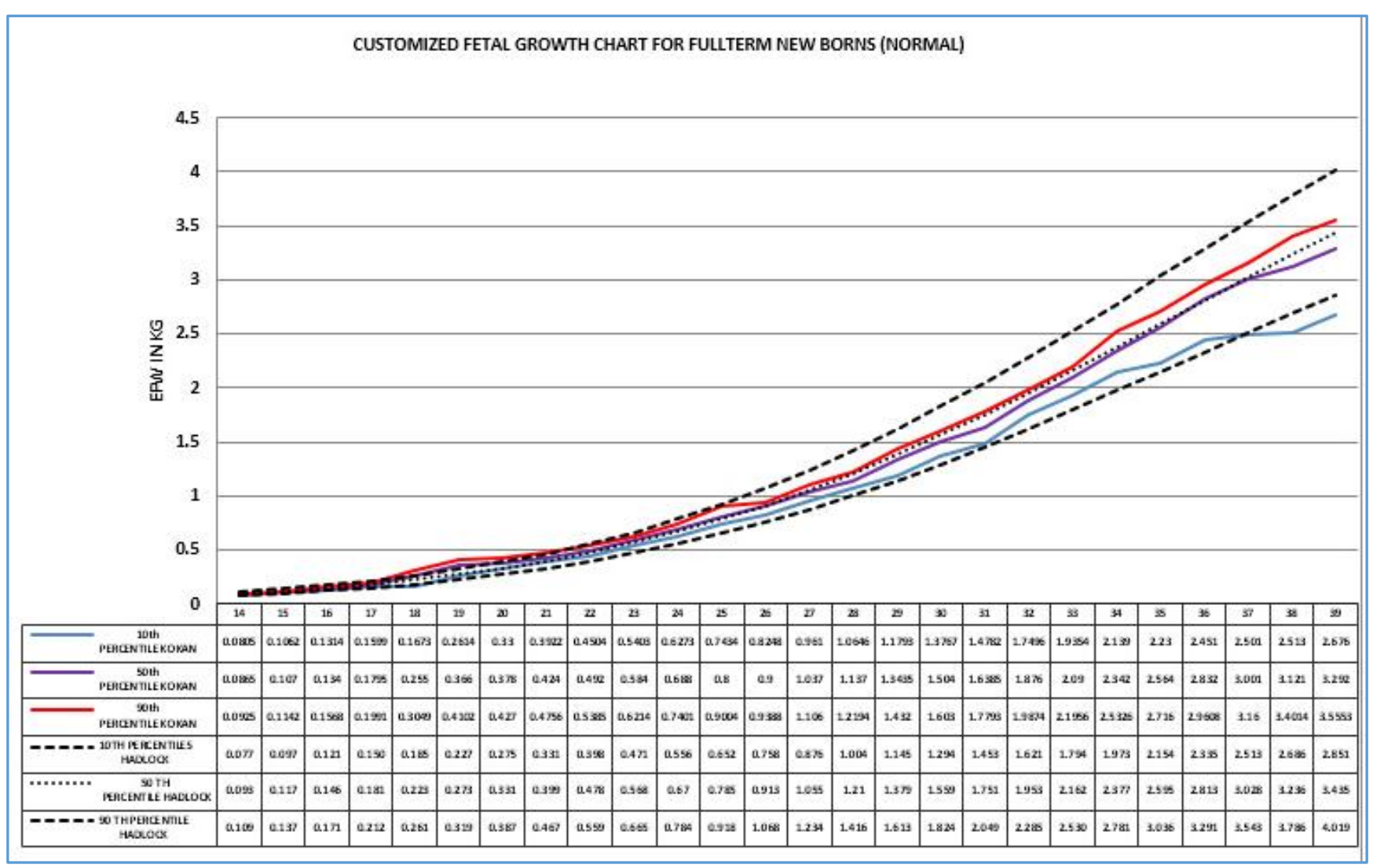

Table 4. Customized Foetal Growth Chart for Fullterm Respondents 
5. As per WHO criteria, newborns weighing less than $2.5 \mathrm{~kg}$ are LBW, but in our analysis SGA were $9.89 \%$, AGA were $80.40 \%$ and LGA were 9.71\%.

\begin{tabular}{|c|c|c|}
\hline Observation for Kokan & Frequency & Percentage \\
\hline Small for Gestational Age $(\mathrm{SGA})<2 \mathrm{~kg}$. & 158 & 9.89 \\
\hline Appropriate Gestational Age(AGA) 2 to $3.09 \mathrm{~kg}$ & 1284 & 80.40 \\
\hline Large Gestational Age(LGA) >3.09 kg & 155 & 9.71 \\
\hline Total & 1597 & 100.00 \\
\hline
\end{tabular}

\section{DISCUSSION}

An average Indian mother is short and thin and gives birth to light and thin baby. Preterm pregnancies account for approximately $10 \%$ of the total pregnancies and are associated with LBW.(5) In our study amongst 1597 women, $12.46 \%$ delivered prematurely which is slightly higher than standard. Total $58.10 \%$ babies were normal weight and $41.89 \%$ were LBW as per WHO criteria. Growth parameters of all babies were compared with Hadlock up to 32-33 weeks of gestation, foetal growth showed linear association with Hadlock standards, afterwards lagging trends were observed for Kokan foetuses. Though $41.89 \%$ babies were reported as LBW according to WHO criteria, customised growth charts of Kokan region pointed out as appropriate for gestational age (AGA). While those $<2 \mathrm{~kg} \&>3.09 \mathrm{~kg}$ were labelled as SGA \& LGA. These LBW babies may be classified as constitutionally small babies but there is no Indian data in such a fashion for comparison. This study may propagate an initiation of research in the field of IUGR in India. Being a retrospective data we could not get the Doppler findings which would have added lot of valuable information to differentiate true LBW and IUGR. All studies indicate that most of the growth in the size of the foetus occurs in the later part of pregnancy. At the end of third month of gestation, the foetus weighs approximately $30 \mathrm{~g}$. The maximum rate of foetal growth is during 32- 38 weeks of pregnancy when the weight virtually doubles. Most of the foetal body fat is deposited between $34^{\text {th }}$ to $40^{\text {th }}$ week of pregnancy. Protein and fat increase rapidly in last 3 months of pregnancy which is reflected by increase in EFW on USG.(6) In Kokan most of the mothers are so probably because there is a supply and demand mismatch during $3^{\text {rd }}$ trimester. In a paper on assessment of foetal gestational age by ultrasonic measurement of bi-parietal diameter in the southern part of Rajasthan, in comparison with foreign studies, it was observed that all the mean values of this study are lower than those of Campbell, Sabbagha et al, Wexler et al and Machado et al with a very few exceptions. However, the observations by Hadlock et al are in close agreement with present study with little exceptions.(7) Present analysis revealed receding trend of foetal growth especially in $3^{\text {rd }}$ trimester, probably attributed to poor maternal reserve.

\section{CONCLUSION}

Study concluded lag of foetal growth beyond 32-33 weeks of gestation in comparison with findings of Hadlock standards may be attributed to compromised nutritional status of Kokan women ascribed with mischief of multifactorial causes for dietary patterns.

\section{Limitations}

1. Record based retrospective analysis hindered in-depth evaluation of growth patterns \& aetiological role.

2. For generalisation of observed trends, there is a need for multicentric prospective analysis. However, this study lays a strong foundation for further research in foetal growth trajectory trends.

\section{ACKNOWLEDGEMENT}

The authors are thankful to the clinicians, radiologist, paramedical and secretarial staff at the B. K. L. Walawalkar Rural Medical College \& Hospital, Kasarwadi, Maharashtra for assistance in preparation of current manuscript.

\section{REFERENCES}

[1] Bharati P, Pal M, Bandyopadhyay M, et al. Prevalence and causes of low birth weight in India. Malays J Nutr 2011;17(3):301-13.

[2] Park. Text book of preventive \& social medicine. $23^{\text {rd }}$ edn. Chapter-Preventive medicine in obstetrics paediatrics \& geriatrics. pp520-607.

[3] Acharya P, Acharya A. Evaluation of applicability of standard growth curves to Indian women by fetal biometry. South Asian Federation of Obstetrics and Gynecology 2009;1(3):55-61.

[4] Yajnik CS, Deshmukh US. Fetal programming: maternal nutrition and role of one carbon metabolism. Rev Endocr Metab Disord 2012;13(2):121-7.

[5] Khot V, Chavan-Gautam P, Joshi S. Proposing interactions between maternal phospholipids and the one carbon cycle: a novel mechanism influencing the risk for cardiovascular diseases in the offspring in later life. Life Sci 2015;129:16-21.

[6] Mother and child nutrition in tropics and subtropics Chapter 4. Nutrition in pregnancy and growth of the fetus. Pp 93-117.

www.oxfordjournals.org/our_journals/tropej/online/ monts_chap4.pdf.

[7] Jaiswal P, Masih WF, Jaiswal S, et al. Assessment of fetal gestational age by ultrasonic measurement of biparietal diameter in the southern part of Rajasthan. Medical Journal 2015;8(1):27-30. 